\title{
SNS Proton Beam Window Disposal
}

\author{
Irina Popova ${ }^{1, *}$, Franz X Gallmeier $^{1}$, Steven Trotter $^{1}$ \\ ${ }^{1}$ ORNL, PO box 2008, MS 6466, Oak Ridge, TN 37831-6474, USA
}

\begin{abstract}
In order to support the disposal of the proton beam window assembly of the Spallation Neutron Source beamline to the target station, waste classification analyses are performed. The window has a limited life-time due to radiation-induced material damage. Analyses include calculation of the radionuclide inventory and shielding analyses for the transport package/container to ensure that the container is compliant with the transportation and waste management regulations. In order to automate this procedure and minimize manual work a script in Perl language was written.
\end{abstract}

\section{Overview}

The Spallation Neutron Source (SNS) in Oak Ridge, Tennessee, is an accelerator driven neutron scattering facility for materials research. Presently SNS operates at 1.4 MW proton beam power incident on a mercury target with a proton beam energy of $1 \mathrm{GeV}$ and $60 \mathrm{~Hz}$ repetition rate. The SNS consists of accelerator facility, target facility, and a world-class suite of neutron scattering instruments.

Some of the components of the facility are scheduled for replacement, because they reach their end-of-life due to radiation induced material damage or burn-up, or because of mechanical failure, or design improvements. All these components must be safely removed, placed in a container for temporary on-site storage, and ultimately transported off-site to a nuclear waste disposal site.

In order to characterize and classify spent components, accurate estimates of radionuclide inventory are performed for components that are exchanged on regular basis such as target vessel and proton beam window module (PBW). A bounding case considering the maximum possible radionuclide inventory, based on a scenario with maximum possible irradiation exposed during the life-time, is established for the respective component. Using these data, the spent component is characterized and classified, and an appropriate container for temporary storage on-site and subsequent transport off-site is suggested. Once the container has been selected, transport calculations for the Department of Transportation (DOT) package are performed to ensure that the transport package is compliant with transportation and waste management regulations. Analyses for the radionuclide inventory and dose rates are performed for each off-site shipment with PBW realistic irradiation history.

The neutronics support analyzes and methods for spent PBW disposal are described in this paper.

\footnotetext{
*Corresponding author: popovai@ornl.gov
}

\section{PBW layout}

The PBW module is mounted in the target monolith, approximately 2.3 meters upstream from the target, and establishes the boundary between the accelerator and target environments. Prior to intercepting the target, full beam power passes through the window, and therefore, the $\mathrm{PBW}$ receives a significant radiation exposure, leading to high activation in the materials.

The PBW module, which is shown in Figure 1 is comprised from the Inconel-718 window and is encased in a 316 stainless steel holder, and water-cooled collimator assembly. The holder is attached to a steel shield plug. The module weighs $3140 \mathrm{~kg}$. Water lines for cooling the assembly exit the shield plug on top, and are shear-cut during PBW module removal activities. These lines along with the interior of the water jacket are dried to a dew point of $-35 \mathrm{~F}$ with compressed air prior to removing the PBW module for disposal.

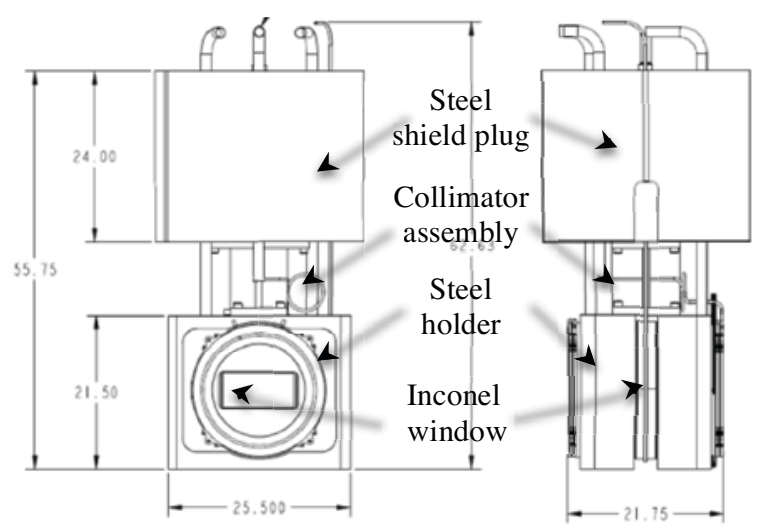

Figure 1. Vertical cross section of the PBW module, front and side views, dimensions are in inches.

The maximum allowable peak damage of steel and Inconel structures is $12 \mathrm{dpa}$. In order to avoid excessive degradation of the materials, periodic replacement of the 
PBW during maintenance outages is scheduled when it approaches its estimated lifetime. Depending on the facility power, these exchanges occur every two or three years. The PBW is safely removed, placed into a handling liner and temporarily stored on site for cooldown. Later, the loaded liner is placed into a transport cask for transport off-site to a nuclear waste disposal facility.

\section{Methods and codes}

Neutronics analyses are performed to support spent PBW deposition. Full three-dimensional radiation transport calculations, using the state-of-the-art code MCNPX Version 2.6.0 [1] and the latest as-built target station model, are performed to simulate the radiation environment of the PBW module, and to calculate isotope production rates due to spallation reactions and the below-20-MeV neutron fluxes in areas of interest. The calculational model is shown in Figure 2. Isotope reaction rates and neutron fluxes are fed into the CINDER90 code [2] using the standardized ACTIVATION_SCRIPT [3] to calculate the PBW radionuclide inventory. Realistic irradiation history and decay time are used in the analyses. In order to obtain radionuclide inventory distributions in the proton beam window, the PBW module is subdivided into 82 cells, and activation calculations are performed based on cell specific isotope production rates and neutron fluxes. Then, to obtain total isotope inventory and decay gammas, the post-processing code ALLCODE is used. This code is part of CINDER90 package and accumulates quantities from all material regions.

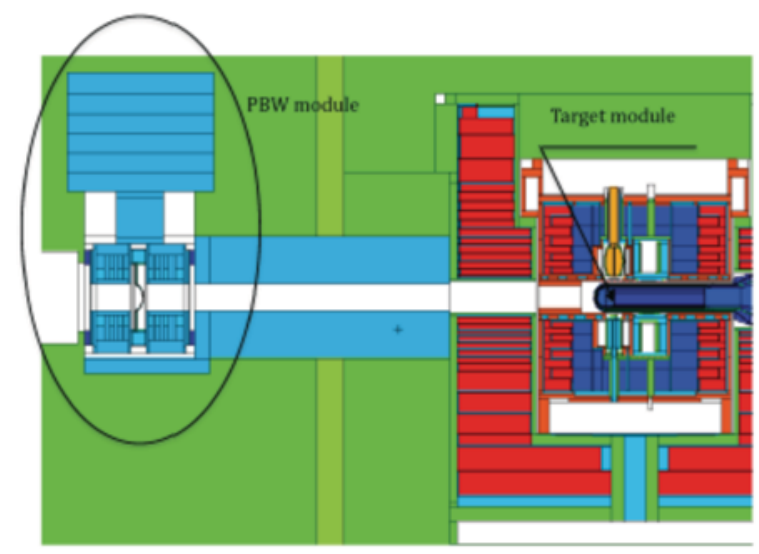

Figure 2. Vertical cross section of the target station including PBW module.

Decay gamma sources for a defined history of buildup and decay are extracted from each cell and compiled to a source term in MCNPX language by running the GAMMA_SOURCE_SCRIPT [4]. The decay gamma source is prepared based on forecasted for transport to the waste disposal facility. The source is utilized in photon transport calculations of the PBW module in the liner and also of the liner containing PBW module once it is placed inside the transport cask for prospective off- site transport time. Furthermore, gamma dose rates at requested locations around both the liner and the cask are provided to assist radiation protection staff planning the respective transport and disposal. For analyses of the residual dose rates, next-event point and ring detectors were applied as well as dose rate mesh tallies to allow for dose rate contours in and around the liner and cask geometries.

For transportation and waste characterization and classification, a report containing isotope inventory, dose rate and transport package description is generated on the basis of the component operation history.

Based on the estimated radionuclide inventory for full beam power $(2 \mathrm{MW})$ for 2 years beam exposure at $5000 \mathrm{~h}$ of operations per year, it was found that the PBW waste profile fits on a per radionuclide comparison into the target vessel waste profile. As such the PBW is handled just as a spent target vessel and transported to off-site disposal using the TN-RAM. A model of the spent PBW module in the liner inserted into a TN-RAM cask is shown in Figure 3.

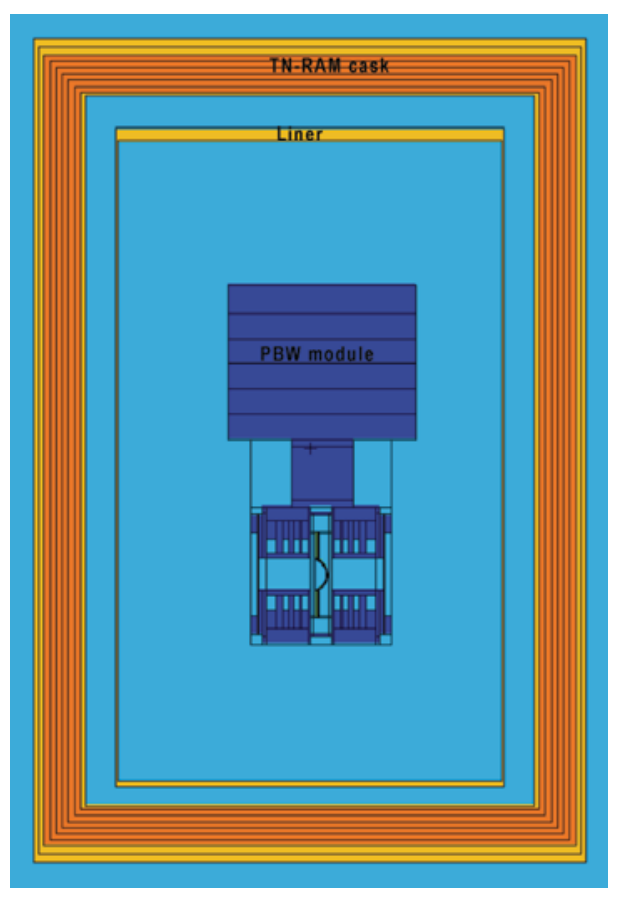

Figure 3. Model of spent PBW module in the liner inserted in TN-RAM cask.

TN-RAM cask model incorporates an inner steel shell of radial thickness 0.75 inches and of 0.5 inches thickness at both the bottom and the top were included as well as the outer steel shell of 1.5 inches radial walls, 2.5 inches walls at the bottom and 2.5 inches walls on the top. The PBW liner is a cylindrical liner with 0.25 inches thick steel sidewalls, a bottom plate of 1 inch thick steel, and a top lid of 2 inches thick steel.

From a transportation and waste management perspectives, supporting analyses with an accurate estimate of the radionuclide inventory and dose rates, assuming realistic irradiation history and decay time, are required for each shipment going to the disposal site. In order to simplify analyses, expedite work, generate a 
report and avoid errors arising from manual preparation of the calculations, a script in Perl language was written.

\section{Script for the analyses}

Script named PBWDISPOSAL.PL is written on Perl language, runs on LINUX machine and, using fluxes and reaction rates from MCNPX output file for transport calculational simulation of the radiation environment of the PBW module, performs neutronics and activation analyses for spent PBW, sorts out data and prepares the final report containing:

- History of irradiation;

- Radionuclide inventories in the PBW module;

- Activity in the PBW module structures after the beam termination versus decay time;

- Gamma contour plots of residual radiation coming from the spent PBW module;

- Predicted dose rates from the surface to the distance $3000 \mathrm{ft}$ from the PBW module;

- Distances from the side and the bottom of the spent PBW module in the liner for which the dose rates fall below $100 \mathrm{mrem} / \mathrm{hr}$ and $5 \mathrm{mrem} / \mathrm{hr}$, respectively.

Script uses 3 input files and supporting files for the analyses. Main input file provides general information such as report number, spent PBW module number, decay history and so on. Second input contains irradiation history. Third input contains cell numbers of PBW to be used in the analyses, which gives flexibility to use different model of the window.

This script:

- Reads input files;

- Creates input files for CINDER analyses, feeds isotope reaction rates and neutron fluxes to the script, and runs activation script for transmutation analyses;

- Creates input file and links for ALLCODE, that combines information by material region;

- Creates input file for GAMMA_SOURCE script and runs it to obtain SDEF card file with residual sources for liner and TN-RAM cask transport analyses for the time of off site transport;

- Runs MCNPX decay gamma transport analyses;

- Prepares tables and figures for the final report using transmutation and transport output files (additional postprocessing script, which extracts data from MCNPX generated mctal file, then formats these data into gnuplot plotting format);

- Creates PDF report using latex, generated report contains information required by waste management.

\section{Example of analyses}

The last PBW that was replaced was PBW \#4. It was in service from August 2012 to July 2014. During that time it was exposed to $8674 \mathrm{MWh}$ proton beam. Off-site transport was tentatively scheduled to occur after 504 days of cooling down. The shut-down activity in the PBW's steel and Inconel structures is shown in Figure 4. Steel structures have higher overall activation because
Inconel structures are less than $0.4 \%$ in the PBW module volume.

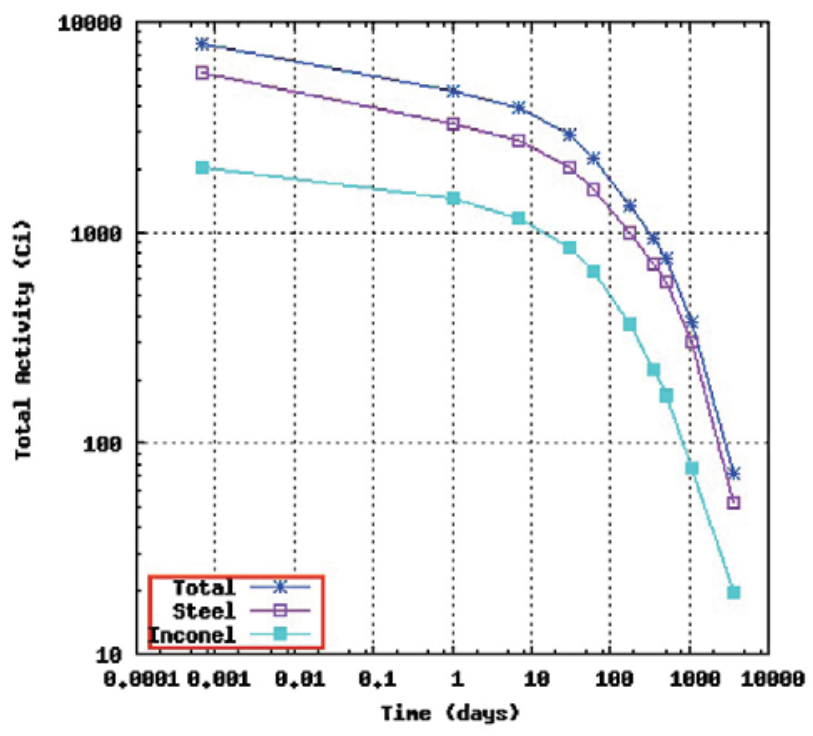

Figure 4. Activity $(\mathrm{Cu})$ in spent PBW module, steel and Inconel structures.

Dose rate contours in and around the PBW module \#4 in the liner after 504 days decay are shown in Figure 5.

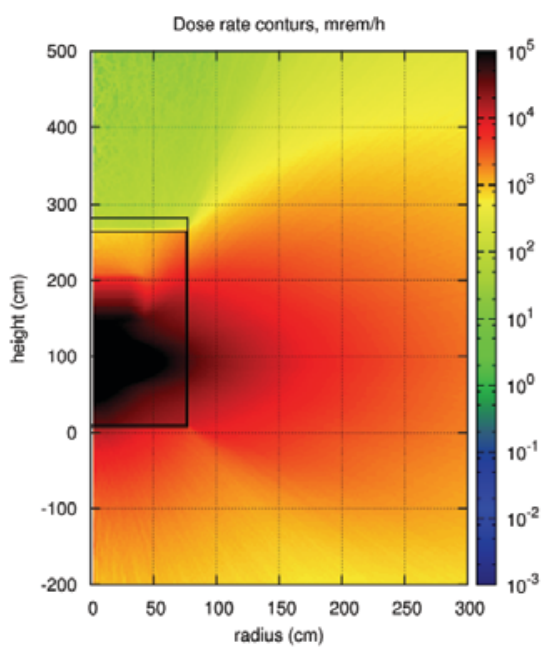

Figure 5. Dose rate contours in and around the PBW module in the liner after 504 days decay.

Dose rate contours in and around the TN-RAM cask loaded with PBW module \#4 in the liner after 504 days decay are shown in Figure 6.

Predicted residual dose rates at specified locations around the PBW module in the liner and the TN-RAM cask loaded with PBW module in the liner after 504 days decay are presented in Table 1. Calculated values have less than $5 \%$ standard deviation. 


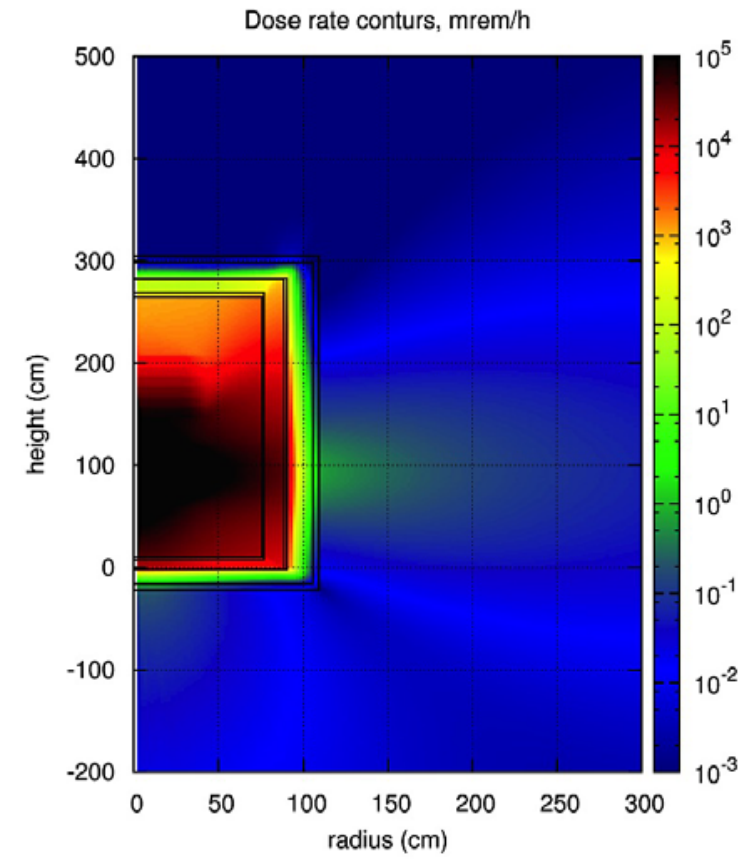

Figure 6. Dose rate contours in and around the TNRAM cask loaded with PBW module in the liner after 504 days decay.

Table 1. Residual dose rates at specified locations around the PBW module in the liner and the TN-RAM cask loaded with PBW module in the liner after 504 days decay, mrem/h.

\begin{tabular}{|c|c|c|}
\hline Location & $\begin{array}{c}\text { Dose Rate } \\
\text { TN-RAM }\end{array}$ & $\begin{array}{c}\text { Dose Rate } \\
\text { Liner }\end{array}$ \\
\hline $0 \mathrm{ft}$ from bottom & $2.01 \mathrm{e}-01$ & $1.41 \mathrm{e}+04$ \\
\hline $1 \mathrm{ft}$ from bottom & $1.13 \mathrm{e}-01$ & $7.00 \mathrm{e}+03$ \\
\hline $3 \mathrm{ft}$ from bottom & $4.68 \mathrm{e}-02$ & $2.74 \mathrm{e}+03$ \\
\hline $10 \mathrm{ft}$ from bottom & $9.02 \mathrm{e}-03$ & $5.06 \mathrm{e}+02$ \\
\hline $25 \mathrm{ft}$ from bottom & $1.87 \mathrm{e}-03$ & $1.03 \mathrm{e}+02$ \\
\hline $50 \mathrm{ft}$ from bottom & $5.13 \mathrm{e}-04$ & $2.89 \mathrm{e}+01$ \\
\hline $125 \mathrm{ft}$ from bottom & $8.81 \mathrm{e}-05$ & $5.37 \mathrm{e}+00$ \\
\hline $0 \mathrm{ft}$ from side & $5.60 \mathrm{e}-01$ & $2.33 \mathrm{e}+04$ \\
\hline $1 \mathrm{ft}$ from side & $3.03 \mathrm{e}-01$ & $1.33 \mathrm{e}+04$ \\
\hline $3 \mathrm{ft}$ from side & $1.32 \mathrm{e}-01$ & $5.70 \mathrm{e}+03$ \\
\hline $10 \mathrm{ft}$ from side & $2.77 \mathrm{e}-02$ & $1.12 \mathrm{e}+03$ \\
\hline $25 \mathrm{ft}$ from side & $5.87 \mathrm{e}-03$ & $2.32 \mathrm{e}+02$ \\
\hline $50 \mathrm{ft}$ from side & $1.60 \mathrm{e}-03$ & $6.73 \mathrm{e}+01$ \\
\hline $125 \mathrm{ft}$ from side & $2.59 \mathrm{e}-04$ & $1.06 \mathrm{e}+01$ \\
\hline
\end{tabular}

\section{Sensitivity analyses}

Residual dose rates analyses were performed to evaluate the sensitivity to impurities, geometry model precision and high-energy physics models. Transport analyses to calculate reactions rates and fluxes in the PBW were done using CEM model and Bertini model for highenergy interactions. Two geometry models were used one is an old, physics geometry model and another is a new one,that was developed according to the engineering drawings. Cobalt (Co) impurity is introduced into stainless steel as $0.1 \%$ in the initial MCNPX run. One run with CEM model was done without Co added to stainless steel. Dose rates, produced with corresponding model on the liner in key locations are shown in Table 2.

Table 2. Residual dose rates for different models, $\mathrm{mrem} / \mathrm{h}$.

\begin{tabular}{|l|l|l|}
\hline Location & $\begin{array}{l}30-\mathrm{cm} \text { from } \\
\text { bottom }\end{array}$ & $\begin{array}{l}30-\mathrm{cm} \\
\text { from side }\end{array}$ \\
\hline $\begin{array}{l}\text { Bertini model, physics } \\
\text { geometry, with Co }\end{array}$ & $1.06 \mathrm{E}+01$ & $1.58 \mathrm{E}+01$ \\
\hline CEM model, no Co & $4.21 \mathrm{E}+00$ & $7.00 \mathrm{E}+00$ \\
\hline CEM model, with Co & $5.79 \mathrm{E}+00$ & $1.08 \mathrm{E}+01$ \\
\hline Bertini model, with Co & $7.03 \mathrm{E}+00$ & $1.33 \mathrm{E}+01$ \\
\hline
\end{tabular}

Adding $0.1 \%$ cobalt to stainless steel increases dose rate about $30 \%$. Bertini versus CEM high energy physics model increases dose rates about 23. Bertini model is used in the analyses.

\section{Conclusions}

Transport and activation analyses are performed to support SNS spent components waste characterization and handling. In order to simplify generating the waste handling report for PBW module, a script in Perl language running on LINUX platform, was written to automate the whole process.

\section{References}

1. C D. Pellowitz, ed., "MCNPX User's Manual, Version 2.6.0," LA-CP-07-1473, Los Alamos National Laboratory, Los Alamos, New Mexico (April 2008). (also see http://mcnpx.lanl.gov).

2. W. B. Wilson, S.T. Cowell, T. R. England, A.C.Hayes, P. Möller, A Manual for Cinder'90 Version 07.4, LA-UR-07-8412, Los Alamos National Laboratory, Los Alamos, (2007).

3. F. X. Gallmeier and M. Wohlmuther, Activation Script Version 1.0 User Guide, ORNL-TM2008/031, Oak Ridge National Laboratory, August 2008. 